\title{
Advances in Aircraft Landing Gear
}




\title{
Other SAE books of interest:
}

Integrated Vehicle Health Management: Perspectives on an Emerging Field

By lan K. Jennions

(Product Code: R-405)

\author{
Aircraft Maintenance \\ By Bruce Aubin \\ (Product Code: T-115)
}

Care and Repair of Advanced Composites

By Keith B. Armstrong, William Cole, and Graham Bevan

(Product Code: R-336)

\author{
For more information or to order a book, contact: \\ SAE INTERNATIONAL \\ 400 Commonwealth Drive \\ Warrendale, PA 15096 \\ Phone: +1.877 .606 .7323 (U.S. and Canada only) \\ or +1.724 .776 .4970 (outside U.S. and Canada) \\ Fax: +1.724.776.0790 \\ Email: CustomerService@sae.org \\ Website: books.sae.org
}




\section{Advances in Aircraft Landing Gear}

By R. Kyle Schmidt

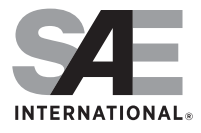

Warrendale, Pennsylvania, USA 


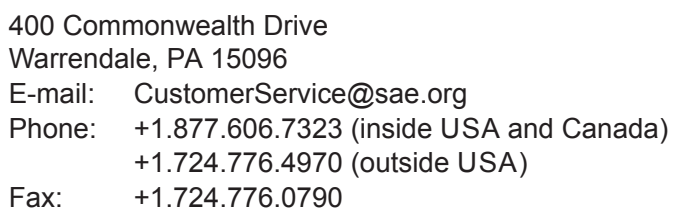

Copyright $\odot 2015$ SAE International. All rights reserved.

Printed in the United States of America

No part of this publication may be reproduced, stored in a retrieval system, distributed, or transmitted, in any form or by any means without the prior written permission of SAE International. For permission and licensing requests, contact SAE Permissions, 400 Commonwealth Drive, Warrendale, PA 15096-0001 USA; e-mail: copyright@sae.org; phone: 724-772-4028; fax: 724-7729765.

\section{Library of Congress Catalog Number 2015947533 SAE Order Number PT-169 http://dx.doi.org/10.4271/pt-169}

Information contained in this work has been obtained by SAE International from sources believed to be reliable. However, neither SAE International nor its authors guarantee the accuracy or completeness of any information published herein and neither SAE International nor its authors shall be responsible for any errors, omissions, or damages arising out of use of this information. This work is published with the understanding that SAE International and its authors are supplying information, but are not attempting to render engineering or other professional services. If such services are required, the assistance of an appropriate professional should be sought.

\section{ISBN-Print 978-0-7680-8218-0 \\ ISBN-PDF 978-0-7680-8246-3 \\ ISBN-epub 978-0-7680-8248-7 \\ ISBN-prc 978-0-7680-8247-0}

To purchase bulk quantities, please contact

SAE Customer Service

e-mail: CustomerService@sae.org

phone: +1.877.606.7323 (inside USA and Canada)

+1.724 .776 .4970 (outside USA)

fax: +1.724 .776 .0790$

Visit the SAE Bookstore at 


\section{Table of Contents}

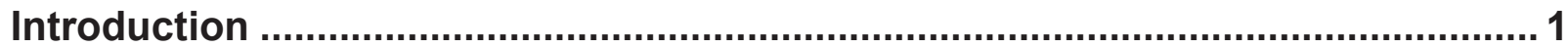

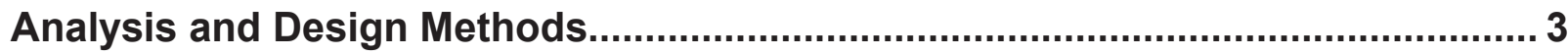

Landing Gear Design in the Conceptual Design Phase (1999-01-5523) ....................5

Sizing the Landing Gear in the Conceptual Design Phase (2000-01-5601)................15

An Automatic Procedure for the Landing Gear Conceptual Design of a

Light Unmanned Aircraft (2013-01-2188) ...........................................................23

An Investigation of Landing Gear Shimmy: Tire Models, Tire Test Methodologies,

Analysis, and Parameter Studies (1999-01-5527) ...............................................

Aircraft Level Steering Runaway Failure Analysis $(2009-01-3136)$.............................65

Bird and Tyre Impact Analysis on Landing Gear (2013-01-9002) ............................71

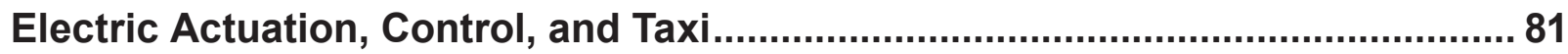

Examination of Aircraft Electric Wheel Drive Taxiing Concept (2008-01-2860) ...........83

Optimal Control Allocation for Electric Aircraft Taxi Systems: A Preliminary Study

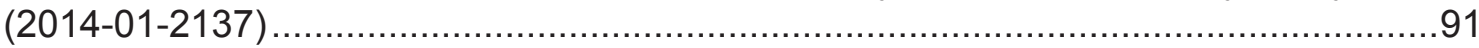

DRESS: Distributed and Redundant Electro-mechanical Nose Wheel Steering System (2009-01-3110)

More Electrical Actuation for ATA 32: Modular Power Electronics \& Electrical Motor Concepts (2010-01-1745).

Hardware Design and Implementation of the Landing Gear Control Algorithm (2014-01-2186)

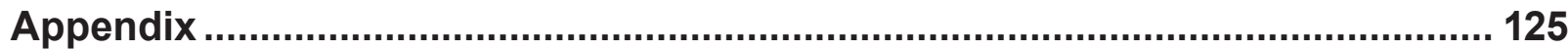

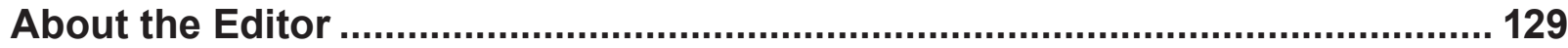

